\title{
Influence of marketing in New Product Development
}

\author{
M. Tamoor Danish \\ School of Business \& Management, \\ Riphah International University, Lahore.
}

\begin{abstract}
Several marketing researchers have concluded that in many organizations the position of marketing decreases and loses its impact. If marketing plays (or should play) a substantial job inside the firm, this capability should have a noticeable voice in new product development (NPD).
\end{abstract}

Keywords: Concluded, Impact, Substantial job

\section{MARKETING AND ITS INFLUENCE}

The job of marketing has been a powerful scene in the previous decades. The most understood stream of research is marketing direction, which is a dominant part of early market research concentrated on (Kohli \& Jaworski, 1990; Narver \& Slater, 1990; Slater \& Narver, 1995). The advancement of market direction invigorates extensive consideration regarding the marketing association in our field (Sinkula, 1994; Slater \& Narver, 1995) and impacts of market direction on firm execution are without a doubt significant (Cano, Carrillat, \& Jaramillo, 2004; Kirca, Jayachandran, \& Bearden, 2005). Market direction by and large contains three central arrangements: client direction, contender direction, and between utilitarian coordination (Han, Kim, \& Srivastava, 1998; Narver \& Slater, 1990). Client direction and contender direction feature the way that organizations should gather data about clients and rivals in the commercial center; and between utilitarian coordination recommends that the data must be dispersed crosswise over capacities inside the association, and that all capacities - not just promoting - should gather and share data about clients and contenders. In view of the proof, the advertising writing for the most part concurs that market data is basic to prevalent business execution (Day, 1994; Moorman, 1995). (Moorman \& Rust, 1999) observational examination finds that marketing's impact clarifies extra fluctuation of budgetary and market execution past market direction. (Verhoef \& Leeflang, 2009; Verhoef et al., 2011) find that predominance of the market work in basic leadership and top supervisory crews can increment other capacities' market-situated exercises. These discoveries feature the way that, past scattering advertising capability over the association, similarly significant is to construct the main job of the marketing capacity in different zones. This uncovers the main kind of impact of promoting in my calculated system: advertising's impact inside the firm.

While specialists have propose the job of marketing's impact in encouraging firm execution (Zhang, 2012), including its impact on new product development (Atuahene-Gima \& Evangelista, 2000; H. Li \& Atuahene-Gima, 1999; Moorman \& Rust, 1999), the influence of marketing is unfortunately found to be declining and losing its importance in many firms (Davies \& Ardley, 2012; Webster Jr, Malter, \& Ganesan, 2005). (Webster Jr et al., 2005) suggest that the disappointment of raising advertising's capacity is because of a few potential reasons, including the unsure meaning of promoting, center around transient execution, powerlessness to gauge marketing efficiency, move in channel power, one-sided on client relationship the executives, move from marketing to deals, and constrained job of showcasing in key arranging. 
In accordance with these discoveries, a discourse about the impact of the advertising capacity has been engaging a lot of consideration (Brown et al., 2005; Verhoef \& Leeflang, 2009).

The second restriction of past research is that market direction mirrors the amount, yet not nature of the conveyance of market insight (Baker \& Sinkula, 1999). In other words, the question is unanswered of how market information influences the decision-making process. (Day \& Montgomery, 1999, p. 5)_ENREF 6 express that analyzing promoting remembers its status for hierarchical direction, yet additionally the utilitarian exercises - that is, "the place and how the significant advertising exercises ought to be performed and how these exercises add to" execution. This proposes the advertising capacity ought to not just lead an association to gathering data about clients and contenders from the commercial center (i.e., outside job of showcasing), yet in addition lead different capacities to scattering and using market data inside the association (i.e., inner job of promoting).

While marketing is losing its capacity at the more significant level of an association, does (should) despite everything it have effect on those littler tables where key choices are made? This inquiry reveals insight into a small scale take a gander at the showcasing capacity and its impact, which I call the "inward promoting of advertising." Past investigations of marketing's impact frequently center on a firm-level or potentially key assessment. These examinations analyze predecessors and results of the promoting capacity's impact, and in this way address the "what" issues (or the amount). Disregarded is the means by which to empower and upgrade such an impact, which underlines the significance of advertising at a lower level (or the quality). NPD groups are the bleeding edges where showcasing comes into contact with other utilitarian units, and in this manner speak to a significant trial of the impact of advertising on useful exercises.

\section{MARKETING'S INFLUENCE WITHIN THE FIRM-CONCEPTUALIZATION}

In certain researches, marketing's impact is inspected in a particular setting. For instance, (Nath \& Mahajan, 2008, 2011) look at CMO in the top supervisory group; and (Davies \& Ardley, 2012) analyze senior promoting the executives in governing body; (Engelen \& Brettel, 2011) explore marketing's impact in a worldwide setting, together with national culture as a key mediator. Those particular settings turn out not to be appropriate to the NPD setting explored in this examination. Increasingly applicable (H. Li \& Atuahene-Gima, 1999) explored, which looks at marketing's impact in the NPD setting and characterizes it as the level of the advertising's capacity in the firm and top supervisory crew. This conceptualization is reliable with (Moorman \& Rust, 1999) and (Verhoef \& Leeflang, 2009) meaning of advertising's impact inside the firm: how much advertising is seen to add to the achievement of the firm comparative with different capacities. I received the conceptualization created by (Moorman \& Rust, 1999), in light of the fact that it centers around the job of showcasing comparative with different capacities. To inspect the job of advertising, it is imperative to remember that marketing's impact is likewise dictated by other capacities' situations inside the association. In this manner, the impact is a relative term. This rationale is additionally reflected in the operationalization of this build.

(Moorman \& Rust, 1999) see advertising's impact as one composite build and estimated it in two viewpoints: (a) choice impact, characterized as the weight given to the showcasing capacity in basic leadership, comparative with different capacities, and (b) saw significance, characterized as apparent significance of the promoting capacity to the firm, comparative with different capacities. (Verhoef \& Leeflang, 2009) characterize it into three classifications: saw impact, top administration regard, and choice impact. To begin with (Verhoef \& Leeflang, 2009), choice impact, got from (Homburg, Workman Jr, \& Krohmer, 1999) work, incorporates 
numerous key issues inside an association, some of which are not profoundly applicable to the NPD setting. Rather (Moorman \& Rust, 1999), choice impact mirrors advertising general effect on basic leadership, which halfway covers top administration regard (Verhoef \& Leeflang, 2009). Therefore, I center around two parts of promoting's impact inside the firm: choice impact and saw significance (Moorman \& Rust, 1999).

\section{NEW PRODUCT DEVELOPMENT CONTEXT}

A run of the mill NPD process incorporates two sections, advancement stages and audit focuses. Most U.S. firms have been utilizing varieties of such a framework to grow new items (Cooper, 1990, 2008). At every advancement position, a cross-useful group carries on different exercises to grow new items, for example, thought and idea testing, starter business examination, item improvement and model, showcase testing, and commercialization. At the audit point that follows every advancement organize, a basic leadership group, regularly comprising of ranking directors, surveys and evaluates the nature of NPD ventures dependent on data produced at the past stage and needs to settle on a choice on whether activities ought to be proceeded. Ranking directors may likewise authorize different criteria to by implication deal with the NPD group process (Sethi \& Iqbal, 2008), which is known as top administration control.

In this research, the cross-practical NPD group as the testing setting to look at the impact of marketing for three reasons. Initial, a cross-practical group is the place advertising comes into contact with different capacities (e.g., building, structure, account, and assembling), and therefore gives a perfect setting to direct an observational trial of the impact of promoting in the interior condition of an association. Second, a dominant part of cross-useful investigations depend on two points of view: data sharing and collaboration between capacities (Fisher, Maltz, \& Jaworski, 1997; Troy, Hirunyawipada, \& Paswan, 2008).

Regardless of significance of the two floods of research, their accentuation lies in communication between utilitarian units. Group administration has been recorded as a test in look into in advancement and a need in best NPD rehearses. Sadly, surviving writing has displayed minimal exact research on the job of pioneers in the advertising association. In NPD, the task head assumes a prompt job in overseeing group exercises and encourages group usage of data. A pioneer can give a convincing motivation to the group to learn and coordinate its social procedures. Investigations of inside promoting likewise offer help to the job of pioneers. (Lam, Kraus, \& Ahearne, 2010) an innovator in the promoting association as the "good example" or social referent. They propose that workers experience experiential gaining from good examples in the association, and they locate that center administrators can impact lowerlevel sales reps' regard for and enthusiasm for clients and contenders. This learning procedure creates shared personality between the pioneer and their subordinates, which further improves execution. In the NPD group, venture pioneers are frequently center directors. In this condition, an undertaking chief has direct correspondence to colleagues and gives guidelines to them with respect to group exercises. In this sense, the venture head is a good example for embracing new data. Additionally, the advancement of new items frequently includes high market vulnerability and thusly finding out about clients and contenders turns out to be particularly significant for colleagues in the improvement procedure. The pioneer assumes the job of reference for colleagues to get the hang of approaching data. Concerning impacts of the NPD venture pioneer, I keep up that there is space for a third view on the cross-practical research, past data sharing and collaboration: The wellspring of market data can impact the task head, who further effects the group use of market data? This perspective is past assessment between practical units, and underlines the adequacy of the interceding job of group pioneers. A cross-practical NPD group is normally straightforwardly driven by a center 
supervisor (e.g., item administrator), who arrange exercises among various capacities, in this way offering me a perfect setting to analyze the source-pioneer group interface. In this way, the NPD venture pioneer is the influence analyzed in the reasonable system. Third, earlier research on relational impact strategies frequently centers on inside capacity assessment - that is, information assortment center around bosses and subordinates working in a similar office. In a cross-utilitarian group, working elements vary. Individuals from various offices cooperate for a transitory extend in the meantime still have personality of their own specialties. How does the promoting capacity impact different others? How does the wellspring of market data can utilize various methodologies to impact other (transitory) colleagues? These inquiries shed light on assessment of the cross-practical NPD group. Truth be told, as the talk of calculated model testing will demonstrate, showcasing's impact inside the firm and a few impact strategies were surely found to vary from impacts determined in different settings analyzed in the writing.

\section{NEW PRODUCT DEVELOPMENT PERFORMANCE}

The reason for providing and using market data is to upgrade NPD execution. In this exploration, NPD execution alludes to two broadly analyzed measurements: result based and process-based. For result based execution, I center on item imaginativeness and new product advantage; for process-based execution, I center on improvement speed. Product imaginativeness alludes to the level of item oddity and its capability to change thinking and practice; new item advantage alludes to new item execution contrasted with contenders' current items; and advancement speed alludes to the pace at which the NPD group makes an interpretation of the item ideas to the new item. These proportions of execution are three of the most basic results in NPD. An incredible number of past examinations have inspected impacts of market data on result based execution. For instance, (T. Li \& Calantone, 1998) handling market data uplifts new item advantage; incorporating market data improves advancement execution. Sharing business sector data builds advancement endeavors; and using market data increments new item inventiveness. Notwithstanding the development considers, writing of market direction for the most part proposes that sharing data about clients and contenders is a basic method to accomplish predominant execution. A surge of research (Kohli, Jaworski, \& Kumar, 1993) sees advertise direction as a conduct develop, which proposes that age, dispersal, and responsiveness to data about clients and rivals in the association can expand business execution. This thought has been analyzed in the advancement setting, where positive connections have been found.

Moreover, as usage of market data can develop shared comprehension, it abbreviates dialog time and lessen the troubles of understanding language utilized by the wellspring of market data (Griffin \& Hauser, 1996). Moreover, since usage of market data can satisfy other colleagues' requirements for data about the commercial center (e.g., clients and contenders), their dynamic quest for advertise knowledge diminishes so time and endeavors are spared. Utilizing such accessible market data will frame the congruity with NPD arranging and activities (Rindfleisch \& Moorman, 2001). Moreover, use of market data empowers colleagues to quick tap client needs and contender practices, in this manner productively assembling basic comprehension of the commercial center, this can accelerate the way toward growing new items.

\section{MARKETING'S INFLUENCE INSIDE THE FIRM}

In accordance with past investigations, advertising's impact is characterized as the estimation of the promoting capacity inside the firm as how much it is seen to add to the achievement of the firm comparative with different capacities (Moorman \& Rust, 1999; Verhoef \& Leeflang, 2009). While promoting's impact influences the association's vital choices and advancement 
results, it tends to be brought into the lower-level group exercises, where advertising researchers have focused on the NPD setting. Following this rationale, I inspect impacts of advertising's impact inside the firm on the NPD venture pioneer's acknowledgment of market data. On the off chance that the marketing has relatively higher seen impact, the practical force is more prominent in an assortment of exercises inside the association, including NPD. It is no big surprise that apparent advertising's impact prompts improved new item execution (Moorman \& Rust, 1999). Also, social on-screen characters for the most part rely more upon the high-impact party. On the off chance that the promoting capacity is seen to have more impact inside the firm, the NPD venture pioneer is bound to focus on data created to reflect showcasing bits of knowledge. Besides, showcasing's impact mirrors association wide regard to promoting in different basic leadership undertakings. This empowers the NPD venture pioneer to perceive how promoting adds to vital achievement of the firm and hence brings about their seeing business sector data as being increasingly significant. Last, saw marketing's impact is found to improve an association's market direction (Verhoef \& Leeflang, 2009). A more grounded market direction requires serious cooperation, which use aggregate information. This upgrades understanding between the source and task pioneer on comprehension of clients and rivals in the commercial center. Likewise, advertise direction is joined by a learning direction. Gathering, scattering, and using market knowledge bring about the undertaking chief's craving to learn and comprehend the commercial center so as to drive group execution.

\section{INFLUENCE TACTICS BY THE SOURCE OF MARKET INFORMATION}

As noted over, the six impact strategies that I receive have been applied beforehand in Investigations of marketing's impact, some of which have been observationally evaluated in the NPD setting. The social brain science and the board writing give productive proof about the results of relational impact strategies. I will examine the instruments for the theory improvement especially in the NPD setting and the connection between practical match (and bungle) and relational impact strategies.

Ingratiation: Ingratiation alludes to the strategy that the wellspring of market data gets the venture head feeling great or to consider well the person in question. There are various sorts of ingratiation. Surviving writing has sorted and concentrated on two significant sorts: selfcentered (self-advancement) and target-centered (support rendering). Studies have recommended that self-centered ingratiation doesn't influence administrators' view of representatives. In this manner, in this exploration I center on the objective centered ingratiation. Ingratiation is seen as sweet talk, "which includes a subordinate's conveying sentiments of enjoying and adoration to a chief." They find that this strategy increments the manager's loving of the subordinate as well as their view of comparability to the subordinate. In the NPD setting, enjoying and likeness can fabricate trust between the task chief and source and increment the pioneer's impression of the source's believability. Trust and believability will additionally build the pioneer's acknowledgment of market data provided by the source. Also, the motivation behind this strategy is to endeavor to create constructive effect of the objective as well as to endeavor to manufacture an individual relationship. It is regularly casual in light of the fact that it doesn't really legitimately address the specific reason. In earlier promoting examination, ingratiation utilized by cutting edge workers expands consumer loyalty; sales reps' ingratiation builds their chiefs' enjoying and in this way execution rating. The NPD writing likewise infers the impacts of ingratiation. For instance, casual systems regularly set up a positive picture and along these lines increment the assessment of the source's validity; "casual communication... is important" in the NPD group; casual discourse and kinship ties are powerful for data move - once in a while increasingly viable to trigger the connection of information tie than is formal talk between NPD colleagues. 
Rationality: Rationality alludes to the strategy that the wellspring of market data utilizes consistent contentions and verifiable proof to persuade the undertaking chief of their data. At the point when the source utilizes a discerning strategy, the undertaking head sees their errand related capacities in a positive manner. Data dependent on judiciousness regularly prompts improved occupation related appraisal, for example, relational abilities, believability, and assignment adequacy and responsibility. Furthermore, on the side of the impact of soundness, advertising thinks about by levelheadedness is the best instrument to impact supply channel individuals. Likewise, the venture head may see the source proficient about the NPD task when the discerning strategy is utilized, as data related with levelheadedness is all around developed and clarified and it is less feeling based. Particularly in a NPD group, absence of basic language is regularly a test for associations between colleagues. Utilizing sensible contentions and real proof sets up a shared opinion, where the task head better comprehends the source's report on advertise data.

Exchange: exchange/trade alludes to the strategy that the source makes promise(s) that the undertaking head will get benefits (e.g., doing him/her some help) on the off chance that the person bolsters the source's report on showcase data. While trade as a "delicate" impact strategy, surviving writing neglects to give a predictable perspective on trade. From one perspective, trade is found to increment social adherence by the objective; then again, it is found to cause negative observations by the objective. I keep up this is a direct result of two potential reasons. To start with, the impact heading contrasts. Trade is especially engaging in horizontal and descending impact and wrong in upward impact. Despite the fact that individuals for the most part esteem response, a verifiable supposition that will be that the influencee ought not have more force than the influencer; generally, trade is seen by influencee as arrangement or bartering. Second, it relies on whether the assignment is required or willful. At the point when workers perform willful or additional assignments, trade strategy is increasingly justifiable and acknowledged; else, it causes negative observations, as it must be performed some way or another. In the NPD setting, practical work force are required to take an interest in the improvement procedure. In any case, the development writing regularly finds that there are perceptual holes and in this manner clashes between capacities, in light of the fact that their basically work errands depend on possess offices instead of NPD as a brief assignment. In this sense, the source has some level of their own practical personality and utilize political aptitudes to get consideration on report on showcase data. Trade as a strategy is frequently utilized when the source holds hesitance to work outside of their area of expertise. However, at the group level the venture chief view trade as a wrong conduct in light of the fact that the wellspring of market data is required to play out their assignments and haggling brings about adverse observations and lessen the pioneer's impression of relational likenesses.

Upward Appeal and Coalition: Upward intrigue, alliance, and decisiveness, as a rule, are considered as "hard" impact strategies. Both upward intrigue and alliance includes looking for outer backings from individuals inside or outside of the association. Upward intrigue lies in help from higher administration; and alliance lies in help from peers.

The general reason for the two strategies is to acquire power so as to constrain the use of data by others. Such strategies in the worker chief work connection is frequently seen (by the pioneer) as trying their capacity and ends up being unsuccessful. Likewise, the advertising writing additionally shows the negative impacts of upward intrigue and alliance with regards to individual selling a contrary voice exists in the writing. 
(Sethi \& Iqbal, 2008) inquire about, they inspect impacts of alliance working in growing newto-the-firm items and characterize it as looking for help from the two friends and ranking directors. This develop can be seen as a blend of upward intrigue and alliance in this exploration. The creators contend and find that picking up others' help inside the association can to some degree convince the undertaking audit group to affirm item advancement plans. This is on the grounds that alliance building may empower top administrators to perceive the advantages of new-to-the-firm items to various offices, notwithstanding the NPD group, inside the association. Regardless of a positive perspective on looking for help from the two companions and ranking directors in explore, I guess negative impacts of upward intrigue and alliance on venture pioneer's acknowledgment of market data for three reasons. In the first place, look into neglects to recognize peers (i.e., alliance) from ranking directors (i.e., upward appreal) and hence results may cover the particular impacts of the impact strategies. Second, this examination is especially keen on the source-pioneer connection, which is seen as an upward impact stream. These two strategies have been recommended to be less as often as possible utilized in the upward impact, contrasted with parallel impact and descending impact, on the grounds that the wellspring of market data is hesitant to challenge the pioneer's capacity. The two strategies are probably going to create the pioneer's horrible recognitions. Third, since the source is considered by the NPD group as the provider of significant market data, looking for others' help to the data, somewhat, lessens the pioneer's view of the source's assignment related abilities and mastery, which further diminishing the dependability of that data.

Assertiveness: Self-assuredness alludes to the source's forceful conduct towards the NPD venture pioneer, for example, rehashing data to the pioneer and communicating outrage. As referenced before, while both legalistic supplication (i.e., utilizing organization arrangements) and forcefulness are treated as various builds in some past examinations, (Yukl \& Falbe, 1990) think about them as a composite develop in upward impact strategies, and studies have discovered high focalized dependability when they are seen as one develop (e.g.,(Goebel, Marshall, \& Locander, 2006). Subsequently, this examination considers decisiveness as including legalistic request. Decisiveness regularly causes negative impression of the influencer, and consequently prompts poor appraisal by the objective e.g.,(Thacker \& Wayne, 1995). Research has inferred that confidence is improper and inadequate in the representative head connection (Kipnis, Schmidt, \& Wilkinson, 1980). Also, assertiveness lessens consumer loyalty; decisiveness intensifies item choices.

The negative impacts of this hard strategy could be far and away more terrible in a cross-useful setting, for example, NPD. (Goebel et al., 2006) study impact strategies in cross-practical correspondence. Because of some level of absence of normal language between utilitarian units, it is significant for the source to expand their dependability. Notwithstanding (Goebel et al., 2006), mighty practices turn around others' impression of source believability, which further decreases correspondence quality. Particularly emphaticness is frequently seen unseemly in the upward impact. The validity can be seen even lower by the NPD venture pioneer. In this sense, the NPD venture pioneer is more averse to acknowledge the source's market data.

Practical Match between the Source of Market Information and Project Leader: As the exploration objective (2) states, earlier research regularly accept that the wellspring of market data is the advertising capacity. Truth be told, it is conceivable and conceivable that other utilitarian faculty accept advertising related obligations in NPD. While mulling over the utilitarian foundation of the source is significant, the foundation of the influencee (i.e., venture pioneer) is additionally identified with the manner in which the individual sees the source's 
impact strategies. Accordingly, I look at the directing impact of practical match (or befuddle) on the anticipated connections between six impact strategies and venture pioneer's acknowledgment of market data.

At the point when the source and venture pioneer have the equivalent practical foundation, both the formal and casual systems between them are more grounded, in light of the fact that they base every day undertakings on useful schedules. In this sense, the venture chief is increasingly acquainted with the source's conduct and subsequently constructs possess systems to oblige the source's impact strategies. The individual relationship built up between the source and undertaking pioneer makes it simpler for the last to acknowledge data provided by the previous (Madhavan \& Grover, 1998). Hence, the impact of ingratiation can be fortified when useful match exists. On the other hand, utilitarian crisscross recommends the tie between the source and task pioneer is moderately feeble, in this manner lessening the impact of ingratiation. Also, utilitarian match recommends that the source and task pioneer have normal information and language. Since sanity is a strategy dependent on legitimate contentions and truthful proof, almost certainly, source and undertaking pioneer fabricate shared comprehension by receiving the judicious strategy.

The impacts of negative impact strategies on venture pioneer's acknowledgment of market data are debilitated when the source and undertaking pioneer have the equivalent practical foundation. Utilitarian match between the dyad improves the two gatherings' view of similitudes and groupness. The pioneer's view of closeness have been found to bring about a superior assessment on the source's presentation (Wayne \& Liden, 1995). This can, somewhat, lessen the impacts of negative impact strategies. Moreover, when the source and task pioneer work in a similar capacity, they have more chances of communication. Higher recurrence of cooperation have been found to raise relational loving, which further forms more grounded trust between the dyad (Nicholson, Compeau, \& Sethi, 2001). Accordingly, despite the fact that the source is utilizing negative impact strategies (trade, upward intrigue, alliance, and decisiveness), the task head will break antagonistic recognitions and disguise the source's data. On the other hand, if the source and undertaking pioneer have distinctive practical foundations, the low degrees of likenesses, relational preferring, and trust won't help lessen the impacts of negative impact strategies.

\section{CONCLUSION}

In this paper, influence of marketing on NPD was looked into and broke down. To start with, there was halfway help to the connection between advertising's impact and venture pioneer's acknowledgment of market data. There were two aspects of this construct of marketing's influence. After classifying it into decision influence and perceived importance, I found that only decision influence had a significant impact on project leader's acceptance of market information. The impact of the marketing capacity as one composite develop, keep up that it ought to be operationalized as different measurements. Their examination underlines three viewpoints (saw impact, top administration regard, and choice impact) of marketing's impact, which apply covering, yet recognized, consequences for business execution.

\section{References}

Atuahene-Gima, K., \& Evangelista, F. (2000). Cross-functional influence in new product development: an exploratory study of marketing and R... D perspectives. Management science, 46(10), 1269-1284.

Baker, W. E., \& Sinkula, J. M. (1999). The synergistic effect of market orientation and learning orientation on organizational performance. Journal of the Academy of Marketing Science, 27(4), 411-427.

Brown, S. W., Webster, F. E., Steenkamp, J.-B. E., Wilkie, W. L., Sheth, J. N., Sisodia, R. S., ... Raju, J. S. (2005).

Marketing renaissance: Opportunities and imperatives for improving marketing thought, practice, and infrastructure. Journal of marketing, 69(4), 1-25. 
Cano, C. R., Carrillat, F. A., \& Jaramillo, F. (2004). A meta-analysis of the relationship between market orientation and business performance: evidence from five continents. International Journal of research in Marketing, 21(2), 179-200.

Cooper, R. G. (1990). Stage-gate systems: a new tool for managing new products. Business horizons, 33(3), 44-54.

Cooper, R. G. (2008). Perspective: The stage-gate ${ }^{\circledR}$ idea-to-launch process-update, what's new, and nexgen systems. Journal of product innovation management, 25(3), 213-232.

Davies, M. A., \& Ardley, B. (2012). Denial at the top table: Status attributions and implications for marketing. Journal of Strategic Marketing, 20(2), 113-126.

Day, G. S. (1994). The capabilities of market-driven organizations. Journal of marketing, 58(4), 37-52.

Day, G. S., \& Montgomery, D. B. (1999). Charting new directions for marketing. Journal of marketing, 63(4_suppl1), 3-13.

Engelen, A., \& Brettel, M. (2011). A cross-cultural perspective of marketing departments' influence tactics. Journal of International Marketing, 19(2), 73-94.

Fisher, R. J., Maltz, E., \& Jaworski, B. J. (1997). Enhancing communication between marketing and engineering: The moderating role of relative functional identification. Journal of marketing, 61(3), 54-70.

Goebel, D. J., Marshall, G. W., \& Locander, W. B. (2006). Getting one's own way: An investigation of influence attempts by marketers on nonmarketing members of the firm. Journal of Business Research, 59(7), 829-837.

Griffin, A., \& Hauser, J. R. (1996). Integrating R\&D and marketing: a review and analysis of the literature. Journal of Product Innovation Management: An International Publication of the Product Development \& Management Association, 13(3), 191-215.

Han, J. K., Kim, N., \& Srivastava, R. K. (1998). Market orientation and organizational performance: is innovation a missing link? Journal of marketing, 62(4), 30-45.

Homburg, C., Workman Jr, J. P., \& Krohmer, H. (1999). Marketing's influence within the firm. Journal of marketing, 63(2), 1-17.

Kipnis, D., Schmidt, S. M., \& Wilkinson, I. (1980). Intraorganizational influence tactics: Explorations in getting one's way. Journal of applied psychology, 65(4), 440.

Kirca, A. H., Jayachandran, S., \& Bearden, W. O. (2005). Market orientation: A meta-analytic review and assessment of its antecedents and impact on performance. Journal of marketing, 69(2), 24-41.

Kohli, A. K., \& Jaworski, B. J. (1990). Market orientation: the construct, research propositions, and managerial implications. Journal of marketing, 54(2), 1-18.

Kohli, A. K., Jaworski, B. J., \& Kumar, A. (1993). MARKOR: a measure of market orientation. Journal of Marketing Research, 30(4), 467-477.

Lam, S. K., Kraus, F., \& Ahearne, M. (2010). The diffusion of market orientation throughout the organization: A social learning theory perspective. Journal of marketing, 74(5), 61-79.

Li, H., \& Atuahene-Gima, K. (1999). Marketing's influence and new product performance in Chinese firms. Journal of International Marketing, 7(1), 34-56.

Li, T., \& Calantone, R. J. (1998). The impact of market knowledge competence on new product advantage: conceptualization and empirical examination. Journal of marketing, 62(4), 13-29.

Madhavan, R., \& Grover, R. (1998). From embedded knowledge to embodied knowledge: new product development as knowledge management. Journal of marketing, 62(4), 1-12.

Moorman, C. (1995). Organizational market information processes: cultural antecedents and new product outcomes. Journal of Marketing Research, 32(3), 318-335.

Moorman, C., \& Rust, R. T. (1999). The role of marketing. Journal of marketing, 63(4_suppl1), 180-197.

Narver, J. C., \& Slater, S. F. (1990). The effect of a market orientation on business profitability. Journal of marketing, 54(4), 20-35.

Nath, P., \& Mahajan, V. (2008). Chief marketing officers: A study of their presence in firms' top management teams. Journal of marketing, 72(1), 65-81.

Nath, P., \& Mahajan, V. (2011). Marketing in the C-suite: a study of chief marketing officer power in firms' top management teams. Journal of marketing, 75(1), 60-77. 
Nicholson, C. Y., Compeau, L. D., \& Sethi, R. (2001). The role of interpersonal liking in building trust in long-term channel relationships. Journal of the Academy of Marketing Science, 29(1), 3.

Rindfleisch, A., \& Moorman, C. (2001). The acquisition and utilization of information in new product alliances: A strength-of-ties perspective. Journal of marketing, 65(2), 1-18.

Sethi, R., \& Iqbal, Z. (2008). Stage-gate controls, learning failure, and adverse effect on novel new products. Journal of marketing, 72(1), 118-134.

Sinkula, J. M. (1994). Market information processing and organizational learning. Journal of marketing, 58(1), 3545.

Slater, S. F., \& Narver, J. C. (1995). Market orientation and the learning organization. Journal of marketing, 59(3), 63-74.

Thacker, R. A., \& Wayne, S. J. (1995). An examination of the relationship between upward influence tactics and assessments of promotability. Journal of management, 21(4), 739-756.

Troy, L. C., Hirunyawipada, T., \& Paswan, A. K. (2008). Cross-functional integration and new product success: an empirical investigation of the findings. Journal of marketing, 72(6), 132-146.

Verhoef, P. C., \& Leeflang, P. S. (2009). Understanding the marketing department's influence within the firm. Journal of marketing, 73(2), 14-37.

Verhoef, P. C., Leeflang, P. S., Reiner, J., Natter, M., Baker, W., Grinstein, A., ... Saunders, J. (2011). A cross-national investigation into the marketing department's influence within the firm: Toward initial empirical generalizations. Journal of International Marketing, 19(3), 59-86.

Wayne, S. J., \& Liden, R. C. (1995). Effects of impression management on performance ratings: A longitudinal study. Academy of Management journal, 38(1), 232-260.

Webster Jr, F. E., Malter, A. J., \& Ganesan, S. (2005). The decline and dispersion of marketing competence. MIT Sloan Management Review, 46(4), 35.

Yukl, G., \& Falbe, C. M. (1990). Influence tactics and objectives in upward, downward, and lateral influence attempts. Journal of applied psychology, 75(2), 132.

Zhang, H. (2012). The Influence of Marketing in New Product Development. 